\title{
Spatial distribution and fate of perfluoroalkyl substances in sediments from the Pearl River Estuary, South China
}

\author{
Yan Gao ${ }^{a}$, Jianjie Fu ${ }^{a}$, Mei Meng ${ }^{a}$, Yawei Wang ${ }^{\mathrm{a}, \mathrm{b}, \mathrm{c}, *}$, Baowei Chen ${ }^{\mathrm{d}}$, Guibin Jiang ${ }^{\mathrm{a}}$ \\ a State Key Laboratory of Environmental Chemistry and Ecotoxicology, Research Center for Eco-Environmental Sciences, Chinese Academy of Sciences, Beijing 100085, China \\ ${ }^{\mathrm{b}}$ Institute of Environment and Health, Jianghan University, Wuhan 430056, China \\ ${ }^{\mathrm{c}}$ University of Chinese Academy of Sciences, Beijing 100049, China \\ ${ }^{\mathrm{d}}$ Department of Civil and Environmental Engineering, The Hong Kong Polytechnic University, Hung Hom, Kowloon, Hong Kong
}

\section{A R T I C L E I N F O}

\section{Article history:}

Received 22 October 2014

Revised 12 May 2015

Accepted 12 May 2015

Available online 28 May 2015

\section{Keywords:}

PFASs

Sediment

Pearl River Estuary

Risk assessment

\begin{abstract}
A B S T R A C T
In this study, 54 sediment samples were collected from the Pearl River Estuary (PRE) in Southern China to study the spatial distribution and patterns of PFASs in this region. PFAS concentrations in the sediment samples ranged from nd (below detection limit) to $2.41 \mathrm{ng} \mathrm{g}^{-1} \mathrm{dw}$ (dry weight) with an average value of $0.79 \mathrm{ng} \mathrm{g}^{-1} \mathrm{dw}$. PFAS concentrations were higher at the nearshore sampling sites than in the others. Perfluorobutanesulfonate (PFBS) and perfluorohexanesulfonate (PFHxS) were the two dominant compounds among the target PFASs, which may be due to their production and use as PFOS substitutes in the Pearl River Delta (PRD) areas. Significant linear relationships were found between total PFAS concentrations and total organic carbon (TOC) $(R=0.30, p<0.05)$. The preliminary environmental risk assessment indicated that PFOS and PFOA in the regional sediments posed no significant ecological risk to the benthic organisms at present levels.
\end{abstract}

(c) 2015 Elsevier Ltd. All rights reserved.

\section{Introduction}

Perfluoroalkyl substances (PFASs), such as perfluorooctanesulfonate (PFOS) and perfluorooctanoate (PFOA) are produced for consumer and industrial purposes because of their excellent properties of thermal stability, surfactant functions, hydrophobicity and oleophobicity (Lindstrom et al., 2011; Prevedouros et al., 2006). Because of their persistence in the environment (Lindstrom et al., 2011), global distribution including the Arctic (Benskin et al., 2012), bioaccumulation in organisms (Naile et al., 2013), and potential toxicity (Vieira et al., 2013), PFASs have received growing concern worldwide. Perfluorooctanesulfonic acid (PFOS), its salts and perfluorooctanesulfonyl fluoride (PFOSF) have been listed in Annex B of the Stockholm Convention as new persistent organic pollutants (POPs) in 2009 (UNEP, 2009).

The $3 \mathrm{M}$ Company, the largest producer of PFOS in the world, has halted the production of PFOSF in 2002. However, the production of PFOS-related chemicals in China increased rapidly from 2003 to 2006, and the annual production has continued high until now. Up to 2011, about 1800 t of PFOS-related chemicals for both

\footnotetext{
* Corresponding author at: State Key Laboratory of Environmental Chemistry and Ecotoxicology, Research Center for Eco-Environmental Sciences, Chinese Academy of Sciences, P.O. Box 2871, Beijing 100085, China.

E-mail address: ywwang@rcees.ac.cn (Y. Wang).
}

domestic use and export have been produced in China, and nearly half of the national output was for export in recent years (Xie et al., 2013b). Most of the manufacturing plants are located in the southern and eastern part of China, including Hubei, Fujian, Guangdong provinces and Shanghai (Xie et al., 2013b). Recent studies have reported that PFASs could be detected in various matrices in China such as water, seafood, and human blood (Cai et al., 2012; Wu et al., 2012b; Yang et al., 2011; Yeung et al., 2006).

Aquatic transport is supposed to be one of the important long range transport routes of PFASs (Prevedouros et al., 2006). A previous study showed that PFASs discharged into the aquatic environment could distribute in water, particulate and sediment (Ahrens et al., 2010), Sediment plays an important role in the aquatic system. It is the important sink for PFASs and other pollutants (Prevedouros et al., 2006). The river estuary can reflect pollutants being transported from the river to the sea. The Pearl River is one of the largest rivers in south China. The Pearl River Estuary (PRE) located in South China links the Pearl River and the South China Sea. The rapid economic development of the Pearl River Delta (PRD) has brought a large number of pollutants such as trace metals, mercury, DDT (Dichlorodiphenyltrichloroethane) and $\mathrm{HCH}$ (Hexachlorocyclohexane) to the surrounding region (Chen et al., 2012; Shi et al., 2010; Zhang et al., 2002). Moreover, PFASs have already been detected in water, sediment and seafood in the Pearl River and the nearshore region (Loi et al., 2013; Pan et al., 
2014; So et al., 2007; Wu et al., 2012b; Zhao et al., 2014b). However, study of PFASs in the sediments from the Pearl River Estuary and the adjacent marine environment is still limited.

The objective of this work is to carry out a systematic survey to trace the spatial distribution and patterns of PFASs in sediments in the PRE. The factors such as total organic carbons (TOC) and $\mathrm{pH}$ that relate to the accumulation of PFASs in the sediments were also investigated to examine possible sources, anthropogenic impacts, and environmental fate of PFASs in the estuary. Finally, the potential risk of PFOS and PFOA to the aquatic ecosystem was assessed in this region.

\section{Materials and methods}

\subsection{Sample collection}

In this study, 54 surface sediment samples (top 0-5 cm) were collected in 2009 (X1-X17) and 2011 (the rest of the samples), and the sampling sites are shown in Fig. 1. The samples were collected using a grab sampler and then stored in polyethylene bags. The collected samples were kept at $4{ }^{\circ} \mathrm{C}$ immediately. After being freeze-dried at $-50{ }^{\circ} \mathrm{C}$ for three days, the samples were ground to small particles with size of less than $200 \mu \mathrm{m}$. Then the samples were stored in the refrigerator at $-20^{\circ} \mathrm{C}$ until analysis.

\subsection{Standards and chemicals}

Nine PFASs standards (PFBS, PFHxS, PFOS, PFHpA, PFOA, PFNA, PFDA, PFUnDA, and PFDoDA) and two internal standards $\left({ }^{13} \mathrm{C}_{4}\right.$ PFOS and $\left.{ }^{13} \mathrm{C}_{4} \mathrm{PFOA}\right)$ were purchased from Wellington Laboratories (Canada). Methanol (HPLC grade) was purchased from J.T.Baker (USA) and ammonium acetate (HPLC grade) from Alfa Aesar (Ward Hill, MA, USA). Water was prepared using a Milli-Q Advantage A10 system (Millipore Corp., USA). The Oasis-HLB cartridge $(6 \mathrm{cc}, 150 \mathrm{mg}$ ) was purchased from Waters (Milford, MA, USA).

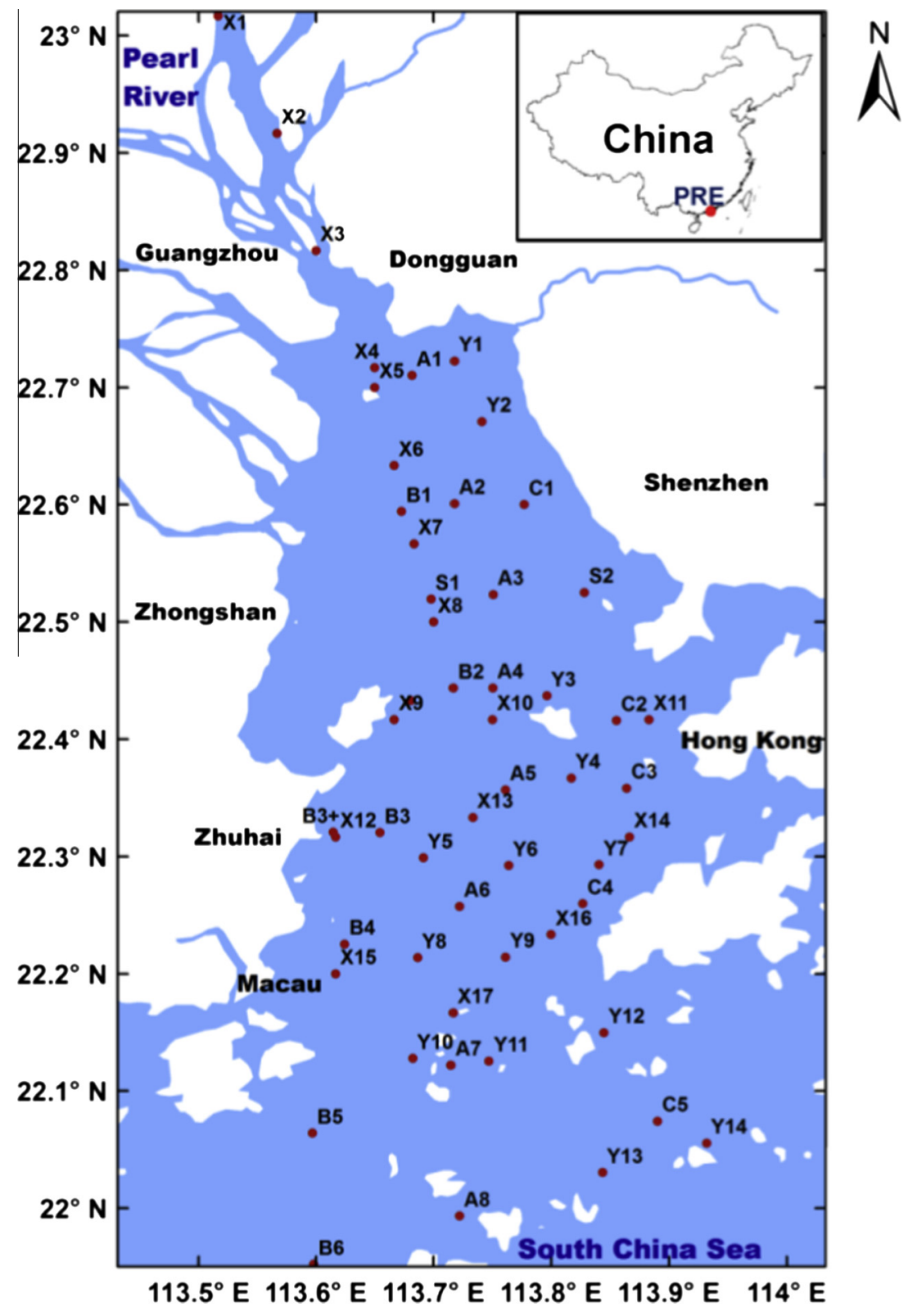

Fig. 1. Study area and sampling sites for sediments. 


\subsection{Sample preparation and instrumental analysis}

The sample pretreatment and instrumental analysis was based on our previous work (Gao et al., 2014; Wang et al., 2010). Sample $(5 \mathrm{~g})$ was added into a $50-\mathrm{mL}$ polypropylene tube and spiked with $5 \mathrm{ng}$ of ${ }^{13} \mathrm{C}_{4}$ PFOS and ${ }^{13} \mathrm{C}_{4}$ PFOA. Methanol $(20 \mathrm{~mL})$ was added and the mixture was sonicated for $20 \mathrm{~min}$ and centrifuged at $3500 \mathrm{rpm}$. The extract was transferred into another polypropylene tube. The remnant was extracted twice by shaking with $10 \mathrm{~mL}$ methanol. The extracts were combined and concentrated to $1 \mathrm{~mL}$ by a nitrogen gas stream at $55^{\circ} \mathrm{C}$. Milli-Q water $(40 \mathrm{~mL})$ was added to the concentrated extract for further cleanup.

The Oasis-HLB solid phase extraction (SPE) cartridge was preconditioned with $7 \mathrm{~mL}$ of methanol and $7 \mathrm{~mL}$ of Milli-Q water. Then the dilute extract was loaded and passed through the cartridge by gravity. Methanol/water $(1: 4,5 \mathrm{~mL})$ was loaded to remove impurities and then the target analytes were eluted with $10 \mathrm{~mL}$ of methanol. The final eluate was concentrated to $1 \mathrm{~mL}$ by $\mathrm{N}_{2}$ at $55^{\circ} \mathrm{C}$ and transferred to an injection vial for instrumental analysis.

The HPLC-ESI(-)/MS/MS system was used for PFAS analysis. The system consisted of an Alliance 2695 high performance liquid chromatograph (Waters Corp., Milford, MA) and a Waters Quattro Premier XE triple-quadrupole mass spectrometer. The sample $(10 \mu \mathrm{L})$ was injected and separated on a Dionex Acclaim $120 \mathrm{C} 18$ column $(5 \mu \mathrm{m}, 4.6 \mathrm{~mm}$ i.d. $\times 150 \mathrm{~mm}$ length; Dionex, Sunnyvale, CA, USA). The mobile phases were methanol and $10 \mathrm{mM}$ ammonium acetate aqueous solution. The elution program was maintained at a flow rate of $1 \mathrm{~mL} \mathrm{~min}^{-1}$, and a dualistic gradient started at $28 \%$ methanol, changed to $5 \%$ methanol at 4 min linearly, returned to $28 \%$ methanol at 7 min linearly, and then was maintained for $3 \mathrm{~min}$.

\subsection{Quality assurance and quality control}

No polytetrafluoroethylene (PTFE) or other fluoropolymer materials was used during sample collection, transport, storage, and pretreatment. The limit of detection (LOD) and the method quantification limit (MQL) were determined as three times and ten times the signal-to-noise ratio based on the matrix samples. The MQLs for all targeted compounds are shown in Table S1. Matrix spike recoveries of different PFASs were in the range of $72.0 \pm 9.9 \%$ to $101.9 \pm 4.8 \%$ (Table S2). To check for potential contamination from the sample processing, procedural blanks were analyzed simultaneously with every batch of seven samples. All of the target compounds in the procedural blanks were below the LOD. More detailed information about the QA/QC can be found in the supplementary materials.

\subsection{Statistical analysis}

The software SPSS 17.0 was used for statistical analysis. Analytical results below LOD were reported as nd (no detection). Correlation analysis was tested by Spearman's rank coefficients. A value of $p<0.05$ was considered significant.

\section{Results and discussion}

\subsection{Concentration and spatial distribution of PFASs in sediments}

The concentrations and detection frequencies of individual compound are shown in Table 1. Among the nine targeted PFASs, only the concentration of PFHpA in the sediment was under LOD in this region. PFHpA is therefore not included in the further data analysis. The detailed information about the individual
Table 1

Concentrations and detection frequencies ( $d f$ ) of PFASs in sediments.

\begin{tabular}{lllllc}
\hline & $\begin{array}{l}\text { Min } \\
\left(\mathrm{ng} \mathrm{g}^{-1} \mathrm{dw}\right)\end{array}$ & $\begin{array}{l}\text { Max } \\
\left(\mathrm{ng} \mathrm{g}^{-1} \mathrm{dw}\right)\end{array}$ & $\begin{array}{l}\text { Mean } \\
\left(\mathrm{ng} \mathrm{g}^{-1} \mathrm{dw}\right)\end{array}$ & $\begin{array}{l}\text { Median } \\
\left(\mathrm{ng} \mathrm{g}^{-1} \mathrm{dw}\right)\end{array}$ & $\mathrm{df}(\%)$ \\
\hline PFBS & $<$ LOD & 1.42 & 0.43 & 0.39 & 88.9 \\
PFHxS & $<$ LOD & 0.73 & 0.19 & 0.17 & 75.9 \\
PFOS & $<$ LOD & 0.32 & 0.12 & 0.12 & 70.4 \\
PFOA & $<$ LOD & 0.15 & 0.03 & $<$ LOD & 35.2 \\
PFNA & $<$ LOD & 0.04 & $<$ LOD & $<$ LOD & 3.70 \\
PFDA & $<$ LOD & 0.11 & 0.01 & $<$ LOD & 14.8 \\
PFUnDA & $<$ LOD & 0.11 & 0.02 & $<$ LOD & 18.5 \\
PFDoDA & $<$ LOD & 0.03 & $<$ LOD & $<$ LOD & 1.85 \\
$\sum{ }_{8}$ PFASs & $<$ LOD & 2.41 & 0.79 & 0.72 & 98.2 \\
\hline
\end{tabular}

concentrations and congener profiles is shown in Table S3 and Fig. S1. The spatial distribution of sediment $\mathrm{pH}$ and TOC was shown in Fig. S2, in the range of 6.68-8.34 and $0.35-2.62 \%$, respectively.

The concentration of the PFASs ( $\sum_{8}$ PFASs) ranged from nd to $2.41 \mathrm{ng} \mathrm{g}^{-1} \mathrm{dw}$, with a mean value of $0.79 \mathrm{ng} \mathrm{g}^{-1} \mathrm{dw}$ and a median value of $0.72 \mathrm{ng} \mathrm{g}^{-1} \mathrm{dw}$. The highest concentration of $\sum_{8}$ PFASs was found at site X11, near Shenzhen City. Overall, $\sum_{8}$ PFASs concentrations were higher in the eastern region (near Shenzhen City and Hong Kong) than in the western sampling area (Fig. 2). A decreasing trend from the coast region to the offshore region was also found. Hierarchical cluster analysis (HCA) showed that samples close to the east bank were clustered as group A, corresponding to the high concentrations at these sites (Fig. 3).

Comparing these results with the results for other pollutants in this region determined previously, PFAS concentrations showed a similar spatial distribution with trace metals such as $\mathrm{Cu}, \mathrm{Ni}, \mathrm{Pb}$, $\mathrm{Zn}$ (Chen et al., 2012). The results indicated that the PFASs and other pollutants might share similar sources related to the high anthropogenic input of the recent industrial activities such as the electroplating and the electronics on the east bank of the PRE.

The comparison of concentrations of PFASs in the sediments in China showed that the mean $\sum$ PFASs concentrations in this work were comparable to the mean concentrations of $\sum$ PFASs in the Liaohe River (2008, 2009) (Bao et al., 2009; Yang et al., 2011), Laizhou Bay (2009) (Zhao et al., 2013), and Taihu Lake (2009) (Yang et al., 2011) but lower than the mean concentrations from the Haihe River, Dagu River (2010) (Li et al., 2011) and riverine sediment from Laizhou Bay in China (2009) (Zhao et al., 2013). Compared to results worldwide, the mean $\sum$ PFASs in this study were higher than in the sediments from the Cantabrian Sea in North Spain (2009) (Gómez et al., 2011), comparable with the sediments from the Ariake Sea in Japan (2004) (Nakata et al., 2006) and the Georgia coast in the USA (2007) (Kumar et al., 2008) but lower than the mean concentrations of $\sum$ PFASs in the sediments from the coast of Korea (2009) (Naile et al., 2013), Sydney Harbor in Australia (2009) (Thompson et al., 2011), and Lake Ontario (2008) (Yeung et al., 2013). The comparison indicated that the PFASs pollution in PRE was at moderate levels from a global perspective.

\subsection{PFAS composition profile and source identification}

HCA indicated that target compounds were separated into perfluorocarboxylates (PFCAs) and perfluorosulfonates (PFSAs), and the concentrations of PFSAs were higher than the concentrations of PFCAs (Fig. 3). Most of the relatively higher concentrations in the sediments for individual compounds were located in the nearshore areas. PFBS was the predominant compound, followed by PFHxS, PFOS and PFOA. The mean concentration of PFBS was $0.43 \mathrm{ng} \mathrm{g}^{-1} \mathrm{dw}$ (median value $0.39 \mathrm{ng} \mathrm{g}^{-1} \mathrm{dw}$ ), with the highest concentration of PFBS at site X11 near Shenzhen and Hong Kong 

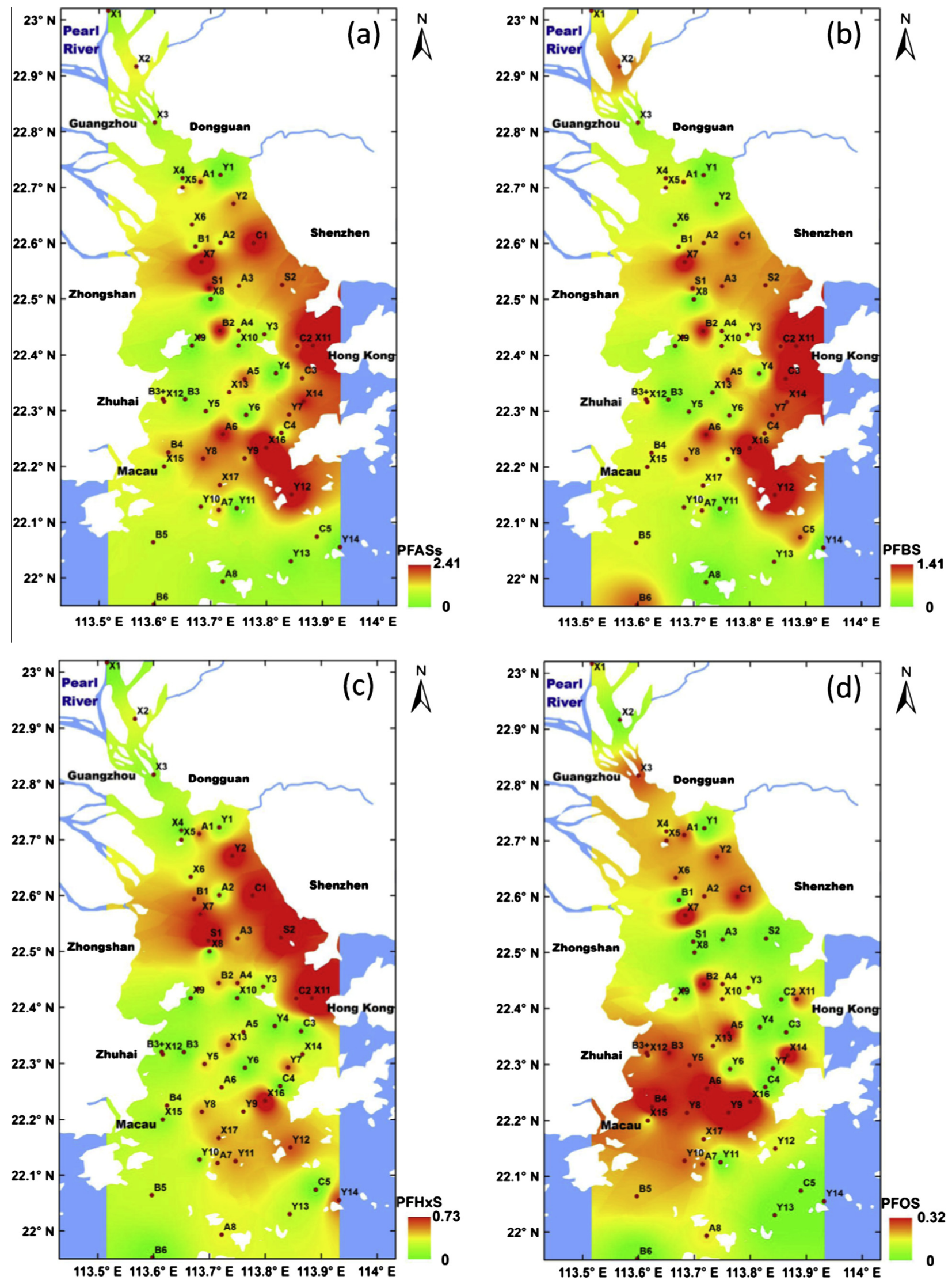

Fig. 2. Spatial distributions of (a) PFASs, (b) PFBS, (c) PFHxS and (d) PFOS (ng g ${ }^{-1} \mathrm{dw}$ ). 


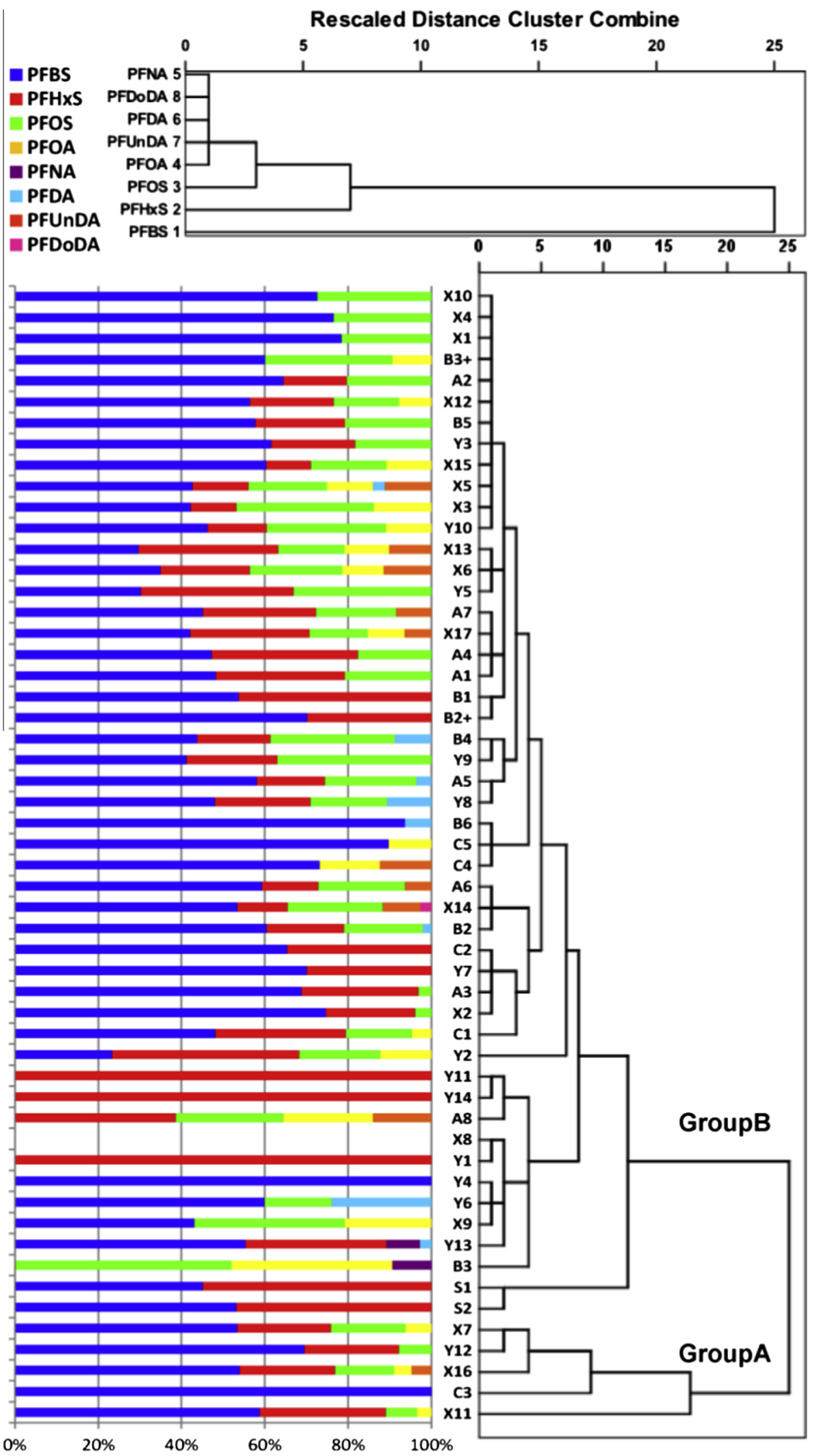

Fig. 3. Individual PFASs composition profile and results of Hierarchical cluster analysis (between groups linkage).

(1.42 $\mathrm{ng} \mathrm{g}^{-1} \mathrm{dw}$ ). The highest concentration of PFHxS and PFOS were at sites X11 and Y9, respectively. The higher proportion of shorter-chain PFASs compared to the longer-chain PFASs may result from the increasing production and use of PFBS and PFHxS as PFOS substitutes in recent years. There are linearly positive relationships among the concentrations of PFBS, PFHxS and PFOS $(p<0.05)$, which implies that they might share similar source and transport routes. Considering the sorption potential of PFASs 
increases with hydrophobicity (Milinovic et al., 2015), the proportion of PFASs with lower hydrophobicity such as PFBS and PFHxS in the possible sources were probably even higher.

The relatively high concentrations of PFBS in the sediments were consistent with the results of the increasing proportions and concentrations of PFBS in the aquatic system in the surrounding area during the past ten years. So et al. reported that in water samples collected in 2004 in PRD, PFBS, PFHxS, PFOS and PFOA were in the range of $<0.03-3.4 \mathrm{ng} \mathrm{L}^{-1}$, nd, $0.9-99 \mathrm{ng} \mathrm{L}^{-1}$ and 0.85-13 $\mathrm{ng} \mathrm{L}^{-1}$ (So et al., 2007). In 2012, Zhang et al. reported that the concentrations of PFBS, PFHxS, PFOS, and PFOA has changed to $0.42-23 \mathrm{ng} \mathrm{L}^{-1}, \quad<0.03-1.00 \mathrm{ng} \mathrm{L}^{-1}, \quad 0.52-11 \mathrm{ng} \mathrm{L}^{-1}$, and $0.71-$ $8.7 \mathrm{ng} \mathrm{L}^{-1}$, respectively, in the water in the same region (Zhang et al., 2013), and the concentrations of shorter-chain PFASs such as PFBS increased which might result from the increasing usage and discharge of shorter-chain PFASs as PFOS substitutes.

Comparing PFASs concentrations from this study with previous results (Fig. 4) (Bao et al., 2009, 2010; Chen et al., 2011; Gómez et al., 2011; Gao et al., 2014; Kumar et al., 2008; Li et al., 2011, 2010; Naile et al., 2013; Nakata et al., 2006; Senthilkumar et al., 2007; Theobald et al., 2012; Thompson et al., 2011; Yang et al., 2011; Zhao et al., 2013; Zhu et al., 2014), PFOS and PFOA concentrations in the sediments from PRE were at the median level compared to results obtained worldwide. However, the concentrations of PFBS and PFHxS in PRE were at a relatively high level. The different concentrations of PFASs from other studies may be due to the different usage in the PRD.

Previous studies noted that the sources of PFOS-related chemicals in the PRD consisted of domestic and industrial emissions including textile treatment, metal plating, fire-fighting, PFOS manufacture, and semiconductor manufacturing (Xie et al., 2013a,b). Comparing to the PFAS concentrations in sediments in PRE with our previous study in the Chinese Bohai Sea (BS), Yellow Sea (YS) and East China Sea (ECS) (Gao et al., 2014), the mean PFOS concentrations were ranked as PRE $>\mathrm{ECS}>\mathrm{YS}>\mathrm{BS}$, in accordance with the results of Xie et al. indicating that the PRD region was one of the regions with the highest PFOS emission density. For PFBS and PFHxS, concentrations in PRE were apparently higher than in the other three sea regions. Based on the estimation of Xie et al., textile treatment was considered to be the largest source of PFOS for the surrounding environment in this region (Xie et al., 2013b). PFOS could still be used for exemptions (UNEP, 2010) in textile treatment, but PFOS substitutes such as PFBS and PFHxS might have been used more in the field of textile treatment in the PRD than in other fields. Although the inventory for the PFOS-related product was still incomplete, the government of China is taking action to reduce the consumption of some PFOS-related products. Investigation and evaluation of PFOS substitutes have been conducted in some industries such as textiles, electroplating, fire-fighting, and pesticides (Lim et al., 2011; Wu et al., 2012a).

\subsection{Factors influencing PFASs distribution}

Previous studies considered that $\mathrm{pH}$ and TOC were important factors influencing PFAS distribution and transport in the sediment (Ahrens et al., 2009; Higgins and Luthy, 2006). In this study, significant linear relationships were found between total PFASs, PFHxS, and PFOS concentrations and total organic carbon (TOC) $(R=0.30$, $0.42,0.44 ; p<0.05)$, indicating that the hydrophobic interaction between PFASs and the organic matter was an important factor affecting the sorption of PFASs on sediment in PRE. Higgins and Luthy reported increasing PFAS concentrations with decreasing $\mathrm{pH}$ by changing the organic matter surface charge (Higgins and Luthy, 2006). Zhao et al. found that with the increasing $\mathrm{pH}$, the surface charge of the sediment might change from positive to negative, resulting in the weakness of the electrostatic attraction between the organic matter surface and the negatively charged PFASs (Zhao et al., 2014a). However, in this study, there was no significant relationship between the PFASs and $\mathrm{pH}$. River erosion and the coastal current may have destabilized the sediment environment, so the adsorption/desorption of PFASs between water and sediment did not achieve a balance under these circumstances.

The particle size could be another important factor. PFAS spatial distribution in this study was similar to the fine fraction distribution in the same region (Chen et al., 2012). The higher PFAS concentrations of the finer sediment samples may be due to the larger specific surface area of the sediment that increased the ability for adsorption for PFASs. Other characteristics such as salinity might also affect the spatial distribution of the PFASs although we did not analyze the salinity of the corresponding water samples. Pan and You have proved that the distribution coefficient (Kd) for PFOS between water and sediment were positively correlated with salinity (Pan and You, 2010). The current within the PRE and the ocean current (So et al., 2004) were also important factors influencing the PFAS distribution. Most of the samples were collected within the estuary. Estuarine currents might play a more important part than the ocean current.

\subsection{Environmental risk assessment of PFOS and PFOA}

The risk quotient (RQ) was used to evaluate the environmental risk assessment (ERA) of PFASs in the sediments in the sampling regions. In this study, RQ was defined as the ratio of measured environmental concentration (MEC) to the predicted no-effect concentration (PNEC). An RQ value below 1 means no potential risk. Because the toxicity data for PFOS and PFOA are scarce, the PNEC selected in this study was calculated by the equilibrium partitioning method, which has been calculated by Zhao et al. in sediments from Laizhou Bay (Zhao et al., 2013). For PFOS, the PNEC was $25 \mu \mathrm{g} \mathrm{L}^{-1}$ in fresh water, derived from the no effect concentration for Mysid shrimp (Brooke et al., 2004). For PFOA, the PNEC was $1250 \mu \mathrm{g} \mathrm{L}^{-1}$ in fresh water, based on the lowest chronic NOEC for inhibition of the growth rate and biomass of the freshwater alga (Colombo et al., 2008). Based on their results, for river sediment, the non-TOC-normalized PNEC for PFOS and PFOA was $4.9 \mathrm{ng} \mathrm{g}^{-1}$ and $86 \mathrm{ng} \mathrm{g}^{-1}$, respectively (Zhao et al., 2013). For marine sediment, the PNEC was ten times lower than the river sediment PNEC (Zhao et al., 2013).

For the river sediments, the maximum value of the non-TOC-normalized MEC was 0.19 and $0.08 \mathrm{ng} \mathrm{g}^{-1} \mathrm{dw}$ for PFOS and PFOA in the sediment collected from site X3. The corresponding RQ was 0.04 and 0.001 , respectively. For the marine sediments, the highest RQ for PFOS and PFOA was 0.65 and 0.02 in the samples collected from sites Y9 and B3, respectively. All of the RQ values were below 1, which meant no significant risk for the benthic organism in the study region. The ERAs for PFOS and PFOA in the sediments in PRE seemed to be negligible due to the relatively low RQ and the phase out of the production of the compounds. However, the potential environmental problem of the short-chain PFASs brought about by the expected increasing usage and production of PFOS substitutes such as PFBS and PFHxS should warrant further study because these compounds have been found in human blood in China with high concentrations (Zhou et al., 2014).

\section{Conclusions}

In summary, the present study revealed the spatial distribution patterns of PFASs in sediments from the Pearl River Estuary. PFBS and PFHxS were the two dominant compounds among the target PFASs, different from other regions in China. The source might be the increasing production and use of shorter-chain PFASs as PFOS 

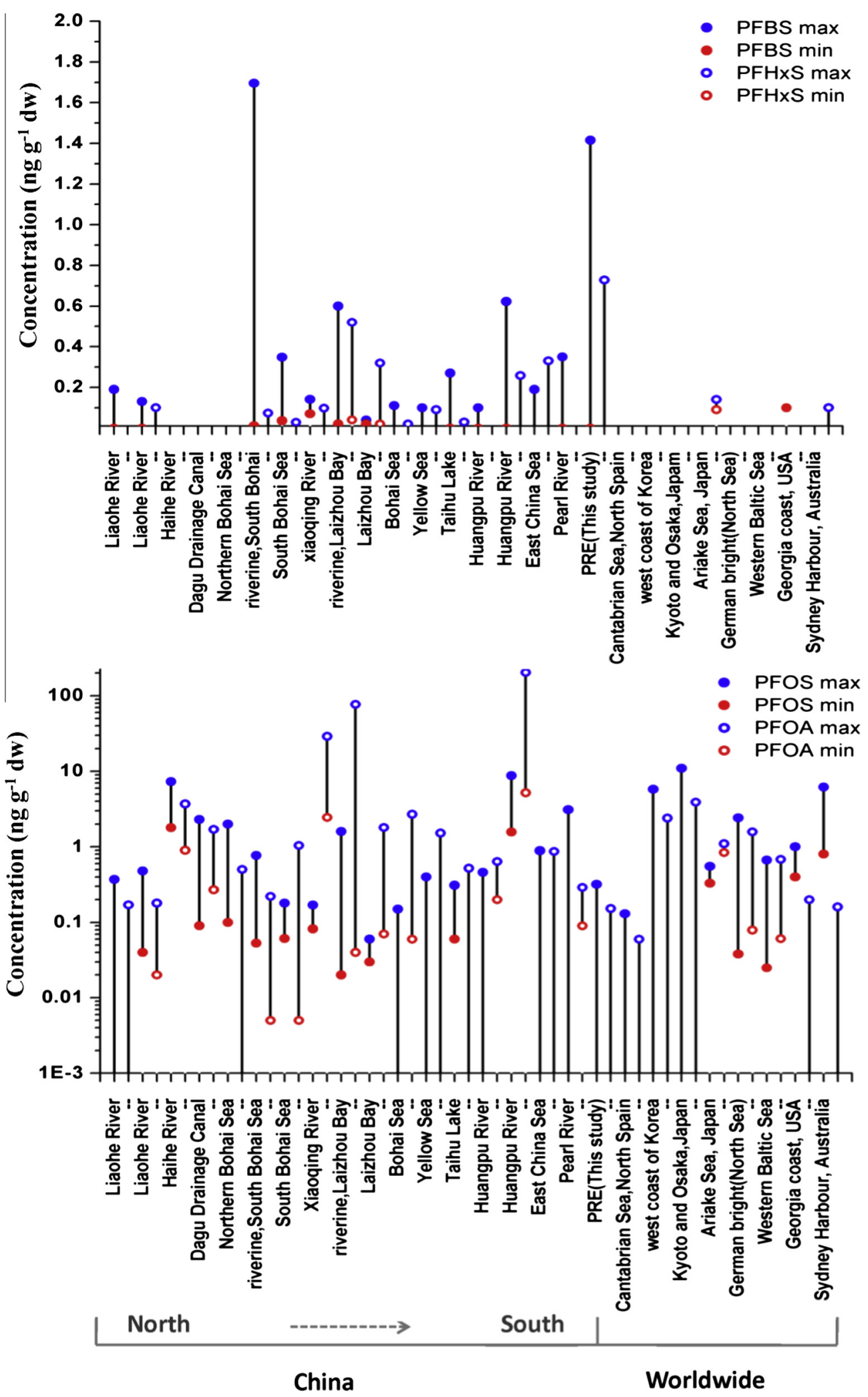

Fig. 4. Comparisons of PFBS, PFHxS, PFOS and PFOA concentrations in sediments in China and worldwide.

substitutes in PRD in recent years. Significant linear relationships were found between total PFAS concentrations and TOC, implying that TOC may play an important role in PFASs distribution. Environmental risk assessment predicted that there was no significant environmental risk for PFOS and PFOA in the sediments of the sampling regions, although PRD is one of the regions with highest emission density of PFOS in China. More studies concerning the environmental risk of the PFOS substitutes should be 
conducted because of the relatively high concentrations of shorter-chain PFASs such as PFBS and PFHxS in the aquatic system in this region.

\section{Acknowledgments}

This work was jointly supported by the projects of the National Natural Science Foundation (21222702 and 21361140359), the Strategic Priority Research Program of the Chinese Academy of Sciences (Grant No. XDB14010400), and the Chinese Academy of Sciences (YSW2013B01). We also would like to thank Prof. Xiangdong Li from The Hong Kong Polytechnic University for the sample collection.

\section{Appendix A. Supplementary material}

Supplementary data associated with this article can be found, in the online version, at http://dx.doi.org/10.1016/j.marpolbul.2015. 05.022 .

\section{References}

Ahrens, L., Yamashita, N., Yeung, L.W.Y., Taniyasu, S., Horii, Y., Lam, P.K.S. Ebinghaus, R., 2009. Partitioning behavior of per- and polyfluoroalkyl compounds between pore water and sediment in two sediment cores from Tokyo Bay, Japan. Environ. Sci. Technol. 43, 6969-6975.

Ahrens, L., Taniyasu, S., Yeung, L.W.Y., Yamashita, N., Lam, P.K.S., Ebinghaus, R, 2010. Distribution of polyfluoroalkyl compounds in water, suspended particulate matter and sediment from Tokyo Bay, Japan. Chemosphere 79 266-272.

Bao, J., Jin, Y., Liu, W., Ran, X., Zhang, Z., 2009. Perfluorinated compounds in sediments from the Daliao River system of northeast China. Chemosphere 77, 652-657.

Bao, J., Liu, W., Liu, L., Jin, Y., Ran, X., Zhang, Z., 2010. Perfluorinated compounds in urban river sediments from Guangzhou and Shanghai of China. Chemosphere $80,123-130$

Benskin, J.P. Muir, D.C.G., Scott, B.F., Spencer, C., De Silva, A.O., Kylin, H., Martin, J.W., Morris, A., Lohmann, R., Tomy, G., Rosenberg, B., Taniyasu, S., Yamashita, N., 2012. Perfluoroalkyl acids in the Atlantic and Canadian Arctic oceans. Environ. Sci. Technol. 46, 5815-5823.

Brooke, D., Footitt, A., Nwaogu, T., Britain, G., 2004. Environmental Risk Evaluation Report: Perfluorooctanesulphonate (PFOS). Environment Agency, UK.

Cai, M., Zhao, Z., Yang, H., Yin, Z., Hong, Q., Sturm, R., Ebinghaus, R., Ahrens, L., Cai, M., He, J., Xie, Z., 2012. Spatial distribution of per- and polyfluoroalkyl compounds in coastal waters from the East to South China Sea. Environ. Pollut. 161, 162-169.

Chen, C., Wang, T., Khim, J.S., Luo, W., Jiao, W., Lu, Y., Naile, J.E., Hu, W., Zhang, X. Geng, J., Bi, C., Li, J., Giesy, J.P., 2011. Perfluorinated compounds in water and sediment from coastal regions of the northern Bohai Seam, China. Chem. Ecol. 27, 165-176.

Chen, B., Liang, X Xu, W. Huang, X., Li, X., 2012. The changes in trace meta contamination over the last decade in surface sediments of the Pearl River Estuary, South China. Sci. Total Environ. 439, 141-149.

Colombo, I., Wolf, W.d., Thompson, R.S., Farrar, D.G., Hoke, R.A., L'Haridon, J., 2008 Acute and chronic aquatic toxicity of ammonium perfluorooctanoate (APFO) to freshwater organisms. Ecotoxicol. Environ. Saf. 71, 749-756.

Gao, Y., Fu, J., Zeng, L., Li, A., Li, H., Zhu, N., Liu, R., Liu, A., Wang, Y., Jiang, G., 2014. Occurrence and fate of perfluoroalkyl substances in marine sediments from the Chinese Bohai Sea, Yellow Sea, and East China Sea. Environ. Pollut. 194, 60-68.

Gómez, C., Vicente, J., Echavarri-Erasun, B., Porte, C., Lacorte, S., 2011. Occurrence of perfluorinated compounds in water, sediment and mussels from the Cantabrian Sea (North Spain). Mar. Pollut. Bull. 62, 948-955.

Higgins, C.P., Luthy, R.G., 2006. Sorption of perfluorinated surfactants on sediments. Environ. Sci. Technol. 40, 7251-7256.

Kumar, K.S., Zushi, Y., Masunaga, S., Gilligan, M., Pride, C., Sajwan, K., 2008 Perfluorinated organic compounds in sediment, aquatic animals including shark from Georgia coast, USA. Organohalogen Compd. 70, 2154-2158.

Li, F., Zhang, C., Qu, Y., Chen, J., Chen, L., Liu, Y., Zhou, Q., 2010. Quantitative characterization of short-and long-chain perfluorinated acids in solid matrices in Shanghai, China. Sci. Total Environ. 408, 617-623.

Li, F., Sun, H., Hao, Z., He, N., Zhao, L., Zhang, T., Sun, T., 2011. Perfluorinated compounds in Haihe River and Dagu Drainage Canal in Tianjin, China. Chemosphere 84, 265-271.

Lim, T.C., Wang, B., Huang, J., Deng, S., Yu, G., 2011. Emission inventory for PFOS in China: review of past methodologies and suggestions. Sci. World J. 11, 19631980.

Lindstrom, A.B., Strynar, M.J., Libelo, E.L., 2011. Polyfluorinated compounds: past, present, and future. Environ. Sci. Technol. 45, 7954-7961.
Loi, E.I., Yeung, L.W., Mabury, S.A., Lam, P.K., 2013. Detections of commercial fluorosurfactants in Hong Kong marine environment and human blood: a pilot study. Environ. Sci. Technol. 47, 4677-4685.

Milinovic, J., Lacorte, S., Vidal, M., Rigol, A., 2015. Sorption behaviour of perfluoroalkyl substances in soils. Sci. Total Environ. 511, 63-71.

Naile, J.E., Khim, J.S., Hong, S., Park, J., Kwon, B.O., Ryu, J.S., Hwang, J.H., Jones, P.D., Giesy, J.P., 2013. Distributions and bioconcentration characteristics of perfluorinated compounds in environmental samples collected from the west coast of Korea. Chemosphere 90, 387-394.

Nakata, H., Kannan, K., Nasu, T., Cho, H.S., Sinclair, E., Takemura, A., 2006. Perfluorinated contaminants in sediments and aquatic organisms collected from shallow water and tidal flat areas of the Ariake Sea, Japan: environmental fate of perfluorooctane sulfonate in aquatic ecosystems. Environ. Sci. Technol. 40, 4916-4921.

Pan, G., You, C., 2010. Sediment-water distribution of perfluorooctane sulfonate (PFOS) in Yangtze River Estuary. Environ. Pollut. 158, 1363-1367.

Pan, C., Ying, G., Liu, Y., Zhang, Q., Chen, Z., Peng, F., Huang, G., 2014. Contamination profiles of perfluoroalkyl substances in five typical rivers of the Pearl River Delta region, South China. Chemosphere 114, 16-25.

Prevedouros, K., Cousins, I.T., Buck, R.C., Korzeniowski, S.H., 2006. Sources, fate and transport of perfluorocarboxylates. Environ. Sci. Technol. 40, 32-44.

Senthilkumar, K., Ohi, E., Sajwan, K., Takasuga, T., Kannan, K., 2007. Perfluorinated compounds in river water, river sediment, market fish, and wildlife samples from Japan. Bull. Environ. Contam. Toxicol. 79, 427-431.

Shi, J., Ip, C.C.M., Zhang, G., Jiang, G., Li, X., 2010. Mercury profiles in sediments of the Pearl River Estuary and the surrounding coastal area of South China. Environ. Pollut. 158, 1974-1979.

So, M.K., Taniyasu, S., Yamashita, N., Giesy, J.P., Zheng, J., Fang, Z., Im, S.H., Lam, P.K.S., 2004. Perfluorinated compounds in coastal waters of Hong Kong, South China, and Korea. Environ. Sci. Technol. 38, 4056-4063.

So, M.K., Miyake, Y., Yeung, W.Y., Ho, Y.M., Taniyasu, S., Rostkowski, P., Yamashita, N., Zhou, B.S., Shi, X.J., Wang, J.X., Giesy, J.P., Yu, H., Lam, P.K.S., 2007. Perfluorinated compounds in the Pearl River and Yangtze River of China. Chemosphere 68, 2085-2095.

Theobald, N., Caliebe, C., Gerwinski, W., Huhnerfuss, H., Lepom, P., 2012. Occurrence of perfluorinated organic acids in the North and Baltic Seas. Part 2: Distribution in sediments. Environ. Sci. Pollut. Res. 19, 313-324.

Thompson, J., Roach, A., Eaglesham, G., Bartkow, M.E., Edge, K., Mueller, J.F., 2011. Perfluorinated alkyl acids in water, sediment and wildlife from Sydney Harbour and surroundings. Mar. Pollut. Bull. 62, 2869-2875.

UNEP, 2009. The new POPs under the Stockholm Convention. <http://chm.pops.int/ TheConvention/ThePOPs/TheNewPOPs/tabid/2511/Default.aspx>.

UNEP, 2010. Guidance on alternatives to perfluorooctane sulfonate and its derivatives. <http://chm.pops.int/TheConvention/POPsReviewCommittee/ ReportsandDecisions/tabid/3309/Default.aspx>.

Vieira, V.M., Hoffman, K., Shin, H.-M., Weinberg, J.M., Webster, T.F., Fletcher, T. 2013. Perfluorooctanoic acid exposure and cancer outcomes in a contaminated community: a geographic analysis. Environ. Health Perspect. 121, 318-323.

Wang, Y., Fu, J., Wang, T., Liang, Y., Pan, Y., Cai, Y., Jiang, G., 2010. Distribution of perfluorooctane sulfonate and other perfluorochemicals in the ambient environment around a manufacturing facility in China. Environ. Sci. Technol. $44,8062-8067$

Wu, G., Yu, L., Hu, L., Peng, Y., Ding, Q., 2012a. Strategies for eliminating production and substituting perfluorooctane sulfonate (PFOS) in China. Asian J. Ecotox. 7, 477-482.

Wu, Y., Wang, Y., Li, J., Zhao, Y., Guo, F., Liu, J., Cai, Z., 2012b. Perfluorinated compounds in seafood from coastal areas in China. Environ. Int. 42, 67-71.

Xie, S., Lu, Y., Wang, T., Liu, S., Jones, K., Sweetman, A., 2013a. Estimation of PFOS emission from domestic sources in the eastern coastal region of China. Environ. Int. 59, 336-343.

Xie, S., Wang, T., Liu, S., Jones, K.C., Sweetman, A.J., Lu, Y., 2013b. Industrial source identification and emission estimation of perfluorooctane sulfonate in China. Environ. Int. 52, 1-8.

Yang, L., Zhu, L., Liu, Z., 2011. Occurrence and partition of perfluorinated compounds in water and sediment from Liao River and Taihu Lake, China. Chemosphere 83, 806-814.

Yeung, L.W.Y., So, M.K., Jiang, G., Taniyasu, S., Yamashita, N., Song, M.Y., Wu, Y., Li, J., Giesy, J.P., Guruge, K.S., Lam, P.K.S., 2006. Perfluorooctanesulfonate and related fluorochemicals in human blood samples from China. Environ. Sci. Technol. 40, $715-720$.

Yeung, L.W., De Silva, A.O., Loi, E.I., Marvin, C.H., Taniyasu, S., Yamashita, N., Mabury, S.A., Muir, D.C., Lam, P.K., 2013. Perfluoroalkyl substances and extractable organic fluorine in surface sediments and cores from Lake Ontario. Environ. Int. 59, 389-397.

Zhang, G., Parker, A., House, A., Mai, B., Li, X., Kang, Y., Wang, Z., 2002. Sedimentary records of DDT and $\mathrm{HCH}$ in the Pearl River Delta, South China. Environ. Sci. Technol. 36, 3671-3677.

Zhang, Y., Lai, S., Zhao, Z., Liu, F., Chen, H., Zou, S., Xie, Z., Ebinghaus, R., 2013. Spatial distribution of perfluoroalkyl acids in the Pearl River of Southern China. Chemosphere 93, 1519-1525.

Zhao, Z., Tang, J., Xie, Z., Chen, Y., Pan, X., Zhong, G., Sturm, R., Zhang, G., Ebinghaus, R., 2013. Perfluoroalkyl acids (PFAAs) in riverine and coastal sediments of Laizhou Bay, North China. Sci. Total Environ. 447, 415-423.

Zhao, L., Bian, J., Zhang, Y., Zhu, L., Liu, Z., 2014a. Comparison of the sorption behaviors and mechanisms of perfluorosulfonates and perfluorocarboxylic acids on three kinds of clay minerals. Chemosphere 114, 51-58. 
Zhao, Y.G., Wan, H.T., Wong, M.H., Wong, C.K.C., 2014b. Partitioning behavior of perfluorinated compounds between sediment and biota in the Pearl River Delta of South China. Mar. Pollut. Bull. 83, 148-154.

Zhou, Z., Shi, Y., Vestergren, R., Wang, T., Liang, Y., Cai, Y., 2014. Highly elevated serum concentrations of perfluoroalkyl substances in fishery employees from Tangxun Lake, China. Environ. Sci. Technol. 48, 3864-3874.
Zhu, Z., Wang, T., Wang, P., Lu, Y., Giesy, J.P., 2014. Perfluoroalkyl and polyfluoroalkyl substances in sediments from South Bohai coastal watersheds, China. Mar. Pollut. Bull. 85, 619-627. 